Association for Information Systems AIS Electronic Library (AISeL)

Spring 3-1-2014

\title{
The Use of Mobiles Among Low-Income Micro- Entrepreneurs: A South Asian Perspective
}

Shazna Zuhyle

shazna@lirneasia.net

Roshanthi Lucas Gunaratne

roshanthi@lirneasia.net

Follow this and additional works at: http://aisel.aisnet.org/icmb2014

\section{Recommended Citation}

Zuhyle, Shazna and Gunaratne, Roshanthi Lucas, "The Use of Mobiles Among Low-Income Micro-Entrepreneurs: A South Asian Perspective" (2014). 2014 International Conference on Mobile Business. 1.

http://aisel.aisnet.org/icmb2014/1 


\title{
THE USE OF MOBILES AMONG LOW-INCOME MICRO- ENTREPRENEURS: A SOUTH ASIAN PERSPECTIVE
}

Zuhyle, Shazna, LIRNEasia, 12 Balcombe Place Colombo 8 Sri Lanka, shazna@lirneasia.net

Lucas Gunaratne, Roshanthi, LIRNEasia, 12 Balcombe Place Colombo 8 Sri Lanka, roshanthi@lirneasia.net

\begin{abstract}
Low-income users in developing economies do not have access to a lot of formal services; however, most have access to a mobile phone. In fact, prior research confirms that the mobile phone is a valuable and often necessary tool for livelihoods of the poor, with a fair number of the lo-income groups using the mobile phone for business or financial related activities. However, based on an empirical survey of 3180 urban low-income micro-entrepreneurs in Sri Lanka, India and Bangladesh, there appears to be instances where users hesitate to consume certain services due to perceived hidden costs. There are also instances where they have found interactions with service providers to be challenging.

This is a descriptive paper of a demand-side survey conducted in Sri Lanka, India and Bangladesh of urban low-income micro-entrepreneurs and their use of mobile phones. It also captures a supply-side study of the mobile network operators in Sri Lanka and Bangladesh. The paper aims to provide recommendations that would bridge the gap in service delivery to the under-served population.
\end{abstract}

Keywords: mobile, low-income, micro-entrepreneur, service delivery, customer relationship management 


\section{$1 \quad$ Managing Customers in the Mobile Industry}

In the past, the telecommunication sector relied heavily on technology and product innovation for competitive advantage. With global competition and relentless technological advances, companies now battle for differentiation through customer services, price and quality of service. The importance of good customer service in order to differentiate themselves from the competition was made clear during interviews with Mobile Network Operators (MNO) in Sri Lanka and Bangladesh.

With the need to differentiate ones' products based on customer services, quality of services, etc, many mobile companies have started to use customer relationship software. Equipping contact centres with sophisticated systems that enable agents to have a unified view of customers including but not limited to personal details, billing information and previous complaints in order to be able to make decisions based on real time customer data (Haridasan, V., \& Venkatesh, S., 2011).

In some cases MNOs use such systems to create comprehensive profiles and segment the customer base into specific subsets based on criteria such as calls made overseas, the use of smart phones or data-enabled handset etc. This has a number of benefits to a carrier in terms of marketing. By pushing more appropriate services they can increase Average Revenue Per User (ARPU) and fight against churn. Subscribers also stand to benefit significantly from better targeted marketing - with particular perks and incentives tailored to their needs, they can receive more airtime or services for the same budget (Barton J, 2012).

McKinsey (Manuel, N. N., \& Sjolund, M., 2008) recommends that MNOs should use their information systems to micro segment their customer base and send out different pilot offers to each segment. Then extend the offers which were the most effective during the pilot phase, to the whole segment. While this is possible with post paid customers, managing prepaid customers who buy their SIMs from third party vendors can be a challenge. The lack of data integrity makes customer life-cycle management particularly hard to implement in prepaid mobile services. Innovative companies have mined usage patterns to create micro-segments: homogenous groups of as few as 100,000 prepaid customers. They use this segmentation to launch customized marketing campaigns that encourage these groups to spend more (Manuel, N. N., \& Sjolund, M., 2008).

As the competitive landscape of a local market evolves, customers evaluate whether to remain loyal to their current service providers. According to a working paper from Harvard Business School, their decisions are affected in part by the quality of service they have experienced from their current service providers, as well as their expectations about the quality of service they may experience for corresponding prices elsewhere. Accordingly, in choosing which service quality/price bundle to offer, firms face a delicate trade-off. On the one hand, offering higher levels of service quality improves transaction experiences, but it also raises costs, which in turn increases prices and the probability of price-sensitive customer defection. On the other hand, reducing service quality reduces costs, and in turn prices, but it increases the likelihood of losing service-sensitive customers (Ryan W. Buell, Dennis Campbell, Frances X. Frei, 2011).

While technology provides a wealth of information to operators about customers and their preferences, there is also literature about the difficulties customers face due to the excess use of technology by MNOs. A study by Meyer and Schwager which appeared in the Harvard Business Review in 2007, describes the complexities customers face in today's tech savvy environment. Customers have difficulty in trying to figure out the cost of carry-forward minutes versus free calls within a network and how it compares with the cost of other services such as messaging. This same study mentions that the consumers who are tired of trying to navigate through the menus, and being kept on hold, have flooded the web site 'Get Human', which showed how to reach a live person quickly at ten major 
consumer sites (Meyer, C., \& Schwager, A., 2007). Today instructions for more than 400 additional companies have been entered to this site.

The aim of this paper is to identify ways in which low-income users consume mobile services and the difficulties they face. After having studied customer relationship management practices of Sri Lankan, Indian and Bangladeshi MNOs, based on interviews with MNOs in the respective countries and analysing the demand-side survey of low-income micro-entrepreneurs, recommendations are provided to improve service delivery.

\section{Customer Lifecycle Management in Sri Lanka and Bangladesh}

Targeting customers: In both Sri Lanka and Bangladesh conventional advertising methods such as newspapers, radio, television, shop branding etc. are used. They also rely on customer referrals. It is illegal to do comparative advertising against other operators in Bangladesh, but Social Network Analysis is legal, where many operators analyze their customer call patterns and identify high value customers from other networks who are then given special offers to switch. This practice is carried out routinely and is a common in Bangladesh. So much so, that in some instances even CXO level staff of one operator has been approached (unknowingly) with offers to switch to a competitor network. In Sri Lanka analyzing customers' call patterns is illegal. However, unethical practices that entailed some form of preliminary call pattern analysis were reported. While definitions of low-income and microentrepreneurs deferred, it was found that Bangladeshi MNOs offer more plans targeted to the rural dwellers. One particular operator analyses the Base Transceiver Stations (BTS) which generate the least revenue and conduct promotional campaigns near those BTS usually timed with the local village Bazaar in order to attract more customers from the area. Another Bangladeshi operator bundles cheap handsets with basic features such as radio, torch along with the mobile connection. In both countries micro-entrepreneurs are defined by the number of employees (e.g. 1-10 or below 12). The plans have similar benefits to friends and family groups that offer cheaper or free calls within the group and/or cheaper monthly rentals. However, they do not really address the needs of micro-entrepreneurs, particularly the low-income micro-entrepreneurs. Either way targeting customers is not really practiced as MNOs believe all segments benefit from the current floor prices. However, one Sri Lankan operator has started door-to-door campaigning. The idea behind it is to take the product to the customer and to promote new services, specifically data (a service that has not been traditionally used). The operator believes that having stalls and expecting the customer to walk-in to find out about a product or service that may be perceived to be for the "rich" is a critical factor they overcome by choosing to take the product to the customer. Pricing for broadband and data plans in general is a concept that is difficult to grasp. It is very unlike the per-minute, per-SMS style pricing that customers are used to. "What does per GB mean?", "How much can I do for $x$ amount?" are some questions that perplex the customer. The fact that all benefits and actual pricing plans can be explained simply and in the local language to the customer, the operator says, out-weighs the cost of this resource intensive exercise.

Welcoming / Registering: Similar, straight-forward processes are carried out in both countries. However, in Bangladesh due to the lack of authentic self identification documents the process of activating a SIM is longer.

Know you customer: With the increase of competition in the mobile telecom sector, it is necessary to understand customer behaviour and respond accordingly. Most operators in both countries segment their customer base according to the average monthly bill and age on network (AoN). Other operators also segment the customer base according to prepaid and postpaid and treat them differently. The operators in both countries also conduct analyses on customer behaviour. In Bangladesh, the operators 
estimate the age of customers, through their behaviour rather than through documentation due to high level of counterfeit documentation.

The contact centre is one of the most common ways in which a customer interacts with the MNO. In most cases there is an active effort in promoting the IVR and USSD methods instead of talking to an agent in the case of enquiries which could be serviced by self. One Bangladeshi operator actually redirected any calls which could be answered by the IVR such as queries on phone balances, ring tones etc. In Sri Lanka however, the general consensus is that all calls will be answered and queries dealt with, however IVR will be promoted for future use. On the contrary, one Sri Lankan operator does not actively promote IVR as they are happy to serve the customer whichever way he pleases. In Bangladesh all prepaid customers are charged for a call made to the call centre, and in some instances for postpaid customers too, albeit at a much lower rate. The reason being the rapid increase in calls (from 2,000 to 26,000 a day) when free calls were offered. Sri Lankan operators too charge for calls to the contact centre from prepaid connections, usually from the third call onwards.

\begin{tabular}{|l|l|l|}
\hline Contact centre data & Sri Lanka & Bangladesh \\
\hline $\begin{array}{l}\text { Number of calls per day per } \\
\text { employee }\end{array}$ & 75 & $100-150$ \\
\hline Percentage of repeat calls & $15 \%$ & $3-5 \%$ \\
\hline First call resolution & $40 \%-75 \%$ & $95 \%$ \\
\hline Average time to resolve & 15 mins & $\begin{array}{l}\text { Greatly varies depending on the } \\
\text { issue/ query }\end{array}$ \\
\hline Average waiting time & $\begin{array}{l}18 \text { seconds to 1:24 mins } \\
\text { the range provided by different } \\
\text { MNOs) }\end{array}$ & $\begin{array}{l}10 \text { segmentation, post paid high } \\
\text { segming depends on } \\
\text { value customers wait much less } \\
\text { than normal customers }\end{array}$ \\
\hline Average call duration & $2: 40$ mins & $2: 33$ mins \\
\hline Percentage of abandoned calls & & $<0.5 \%$ \\
\hline
\end{tabular}

Table 1: Selected Contact Centre Data

Managing Problems: Responding to customer complaints is a crucial aspect of customer care. Most MNOs have an integrated system that automatically sends complaints entered in to the system to alert technical staff. Even with less sophisticated systems, the information and process flow follows a similar route. After resolution, an evaluation on the interaction with the contact centre is requested from the customer via SMS. While practices and internal processes differ by MNO, it was interesting to note that a Bangladeshi MNO propagates the message of 'customer is king' by having the CXO level staff make personal calls to randomly selected customers who have lodged complaints and take personal responsibility to ensure the problem is resolved. Network coverage related issues, Value Added Service (VAS) deactivation and billing related issues are among the top complaints at the contact centres in both countries.

Win-Back: Most operators in Bangladesh do not have proactive win back strategies. They will try to retain post-paid customers who have requested disconnection by offering fee waivers or additional services. In the case of prepaid, a service notification such as ' 5 days to expiry' is automatically sent to customers through a system before their prepaid card expire and special offers are made if they top up before expiry. In Sri Lanka most MNOs have dedicated teams whose main goal is to reduce the churn rates. In the event of voluntary disconnections of post-paid plans, the customers are contacted and all 
attempts are made to retain the customer on the network. With an impressive 'win- back' rate of approximately $40 \%$, it appears that having a dedicated team for this purpose does pay off.

\section{Survey Methodology}

A survey was conducted among the low-income urban micro-entrepreneurs in three countries, Bangladesh, India and Sri Lanka. The survey was set out to understand the use of electricity, mobile and government services. However, this paper is based on the outcome from the mobile section of the survey that captures access and use of ICTs, particularly mobile services and interactions with the service providers. The study defined micro-entrepreneurs as those who employed less than ten hired workers. The hired workers are paid employees or full time equivalent, excluding the owner. This is an adaptation of international definition followed by World Bank and European Commission (Europa, 2003). Low-income is identified as those who occupy B1, B2, C, D \& E in the socio economic category (SEC) classification in Bangladesh and Sri Lanka and SEC C, D \& E in India. In all three countries, only cities or urban localities as defined by the respective national governments were selected for the study. Owners of microenterprises, older than 14 years were included in the study.

In each country, two cities were selected. The capital city and another city which is weaker in terms of governance. The governance was inferred by the proxy indicators related to the human development of the province / state the city is located. The study assumed that low-income micro-entrepreneurs would experience differential efficiency levels in customer services in these two locations due to overall difference in governance levels. In Bangladesh, Dhaka, the national capital city and Gaibandha and Kurigram cities from the Rajshahi Division were selected. In India, New Delhi, the National Capital city and Patna, capital city of Bihar State or province were selected on the basis of data available on cities. In Sri Lanka, Colombo, the national capital city from Western province and four urban centres, Kurunegala and Kuliyapitiya from Kurunegala district and Puttalam and Chilaw from the Puttalam district were selected. As the number of micro-entrepreneurs were inadequate in the selected weaker locations in Bangladesh and Sri Lanka, additional urban centres or cities were selected.

The respondents for the study were selected through a probability sampling method. In Sri Lanka, the A-Z map book published by The Survey Department of Sri Lanka was used. The entire province was divided into square blocks. Using a random number table, blocks were selected. In each block, respondents were found first at the northwest corner and then subsequent interviews were conducted in the same block by continuous walking. In few instances, for the 6-9 workers category, snowball sampling was used to find respondents within the same block. In India, the city is divided into wards by the Election Commission of India. The list of wards was taken and sixteen wards were selected through systematic sampling process. Within each ward, all the streets were listed alphabetically. Every third street was selected and respondents were found for the study. In Bangladesh, cities were divided into wards, then mahallas and then streets. A similar method as in India was followed. As some of the wards were inaccessible due to incessant hartals (public protests) and governmental restrictions, additional wards were selected using the similar process.

The fieldwork was conducted during March - May 2013. After identifying the valid respondents, the response rate for Bangladesh, India and Sri Lanka were $80 \%, 99 \%$ and $86 \%$ respectively. The final sample size is 3180 (Bangladesh - 986, India - 1279 and Sri Lanka - 915). In each country, the respective sample was divided equally between the two locations differed by levels of governance, strong and weak. The numbers were decided after considering the required number of cases for statistical analysis and amount of funds available for the study. In addition there was a qualitative study with 88 participants, conducted as focus groups, ethnographies and in-depth interviews. 
Due to resource and time constraints the research was limited to a few cities in three South Asian countries. The scope of study was also limited to urban centres within the selected cities.

\section{$4 \quad$ What the low-income micro-entrepreneurs say?}

Previous research (Maity, 2012) on the base of the pyramid users (those belonging to SEC D \& E) show that a fair number use the mobile phone for some kind of work, business or financial related activity. The quantitative survey of low-income micro-entrepreneurs confirm that in comparison with other ICTs such as fixed phones and computers, mobile phones are used the most for business purposes; i.e. to get in touch with customers and suppliers. Most respondents of the qualitative study say that the phone is a vital tool for their businesses and lack of connectivity results in missed opportunities.

In fact network connectivity is one of the significant deciding factors when purchasing a new plan (Figure 1). The other most common factor considered by this low-income group is their social network. Friends and family who are existing mobile users play a role in influencing those who are looking to purchase a new mobile connection. Unlike those in the higher income groups, the marginally cheaper calls and in most instances free minutes for on-net calls make a significant difference. It is not uncommon for low-income users to select a service provider and plan based on what the majority have subscribed to. Their social networks matter.

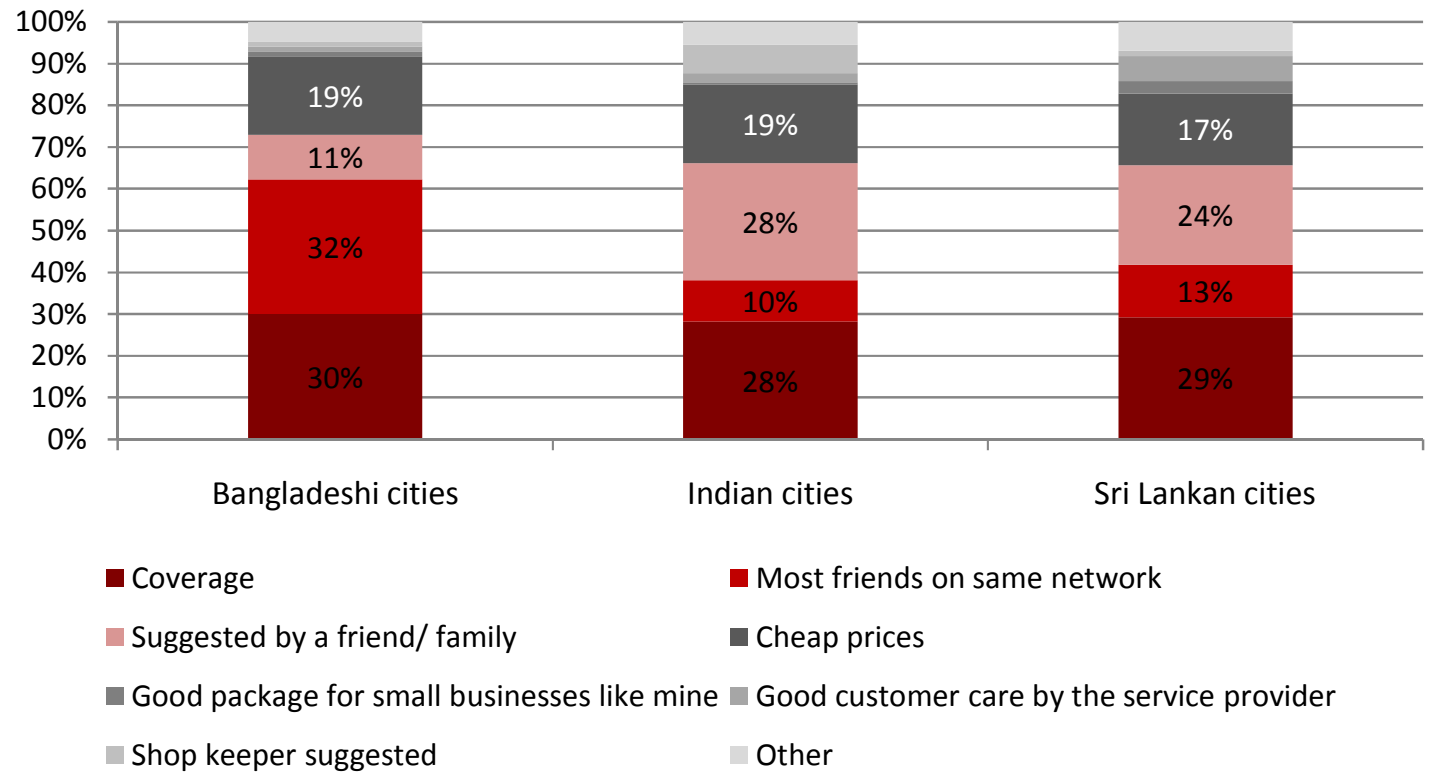

Figure 1: Reasons for selecting a service provider

When phones are used for business purposes one places a higher value on the mobile phone number. It becomes part of your identity. In markets where mobile number portability (MNP) is not offered (e.g. Sri Lanka and Bangladesh where the regulator is planning on implementing MNP) consumers tend to be loyal to the service provider due to the value placed on the phone number, even if there are issues related with service delivery. In comparison with the base of the pyramid users (SEC D\&E) surveyed in 2011 there was less multiple SIM ownership among the low-income micro entrepreneurs. However, multiple SIM ownership is still pertinent; more so in Bangladesh and India (Figure 2). The rationale behind this phenomenon is maximising on on-net tariffs that are cheap or free. The proliferation of 
cheap Chinese handsets that have a dual-SIM capability ease the process of switching between two SIM cards.

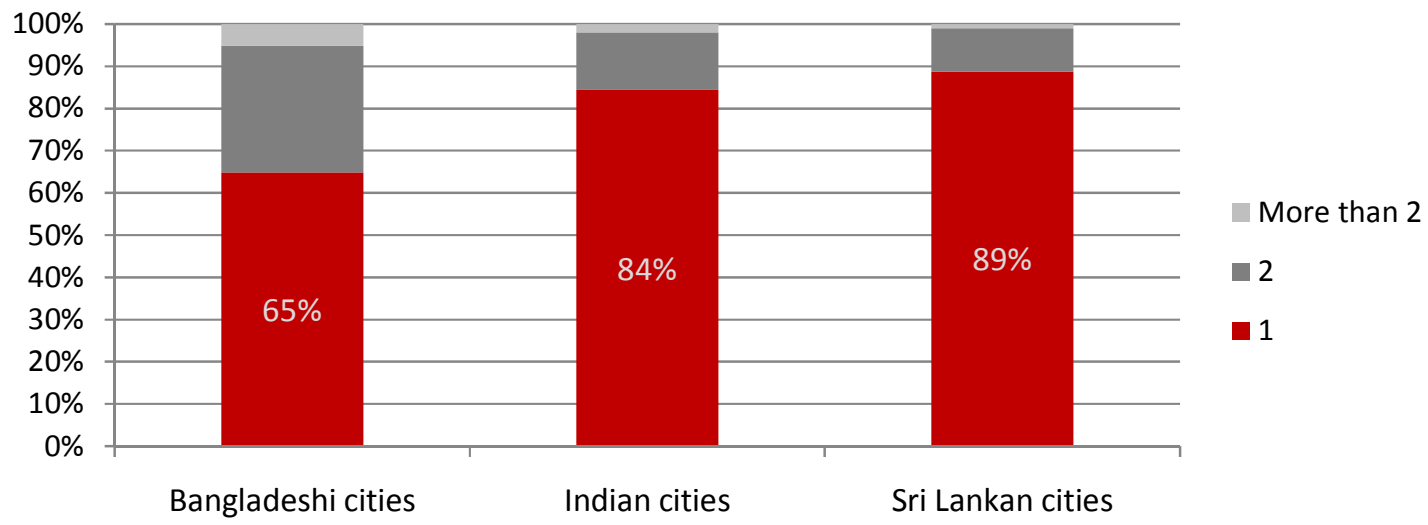

Figure 2: Multiple SIM Ownership among low-income micro-entrepreneurs

Given the two options of voice or exit, the findings from the qualitative study confirms that more users in Sri Lanka are prone to exit without complaining to the MNO when faced with network related issues. The mobile sectors in all three countries surveyed are competitive. For example the HHIs based on market shares, is 2903 in Bangladesh 2430 in Sri Lanka. Bangladesh has six MNOs and Sri Lanka has five. Therefore, consumers have a choice and switching to another prepaid plan is hassle-free. The floor pricing introduced by the Sri Lankan regulator in 2010, poses a challenge for MNOs to compete on cost. Therefore, it is other more-than-voice incentives that capture the market and have the ability, to some extent, to lock-in loyalty. Value added services, mobile payments or any financial service attached to the mobile phone, if customised and targeted to particular market segments can be offered to enhance customer loyalty.

Segmenting the customer base therefore, is vital. Currently in Sri Lanka the market is segmented based on factors such as Age on Network (AoN), monthly expenditure, corporate vs. personal connections, prepaid vs. post-paid etc. These segments are at a very high level and cannot be used asis to encapsulate the essence of a micro segment. The mix of subscribers within the current segment have vastly different profiles and therefore when promotions are offered to the segment, they are not really targeted and are often ignored, initially due to irrelevance and later due to the sheer number of promotional messages one receives. Although VAS related issues were not as significant in the quantitative survey, the qualitative studies in all three countries confirmed that most found the promotional messages overwhelming. As a result, VAS are subscribed to unintentionally, which then leads to subscribers calling the contact centre to request for deactivation (calls made by prepaid users are usually chargeable). Often, the low-income groups realise they have accidentally subscribed to a VAS when the balance on their phone reduces drastically. Some Bangladeshi MNOs use data analytics to micro segment the customer base. In addition, promotional messages are often tested within a small group and are extended to the rest of the segment based on prior success rates. In these countries however, MNOs are challenged with identifying a user (as opposed to a subscriber; i.e. the name under which the connection was purchased), especially in the case of prepaid connections used by the majority of the low-income group. Obtaining a prepaid connection requires some proof of identity; however, there are no restrictions in using a SIM card purchased with someone else's national identification number. Identifying users as opposed to subscribers is one of the biggest challenges faced by the MNOs, which is one of the reasons they use behavioural analytics instead of registration documentation in Bangladesh. 
At present there is no real incentive for low-income micro-entrepreneurs to self identify, as MNOs do not offer specific plans for this group. There are plans for businesses with less than ten employees offered by one of the five MNOs in Sri Lanka and by some of the Bangladeshi operators; however, apart from the usual benefits of offering free minutes, reduced monthly rentals and so on, there is almost no necessity to opt for postpaid connections. In fact bill shock is the main reason for users to continue with or revert to prepaid connections (Figure 3).

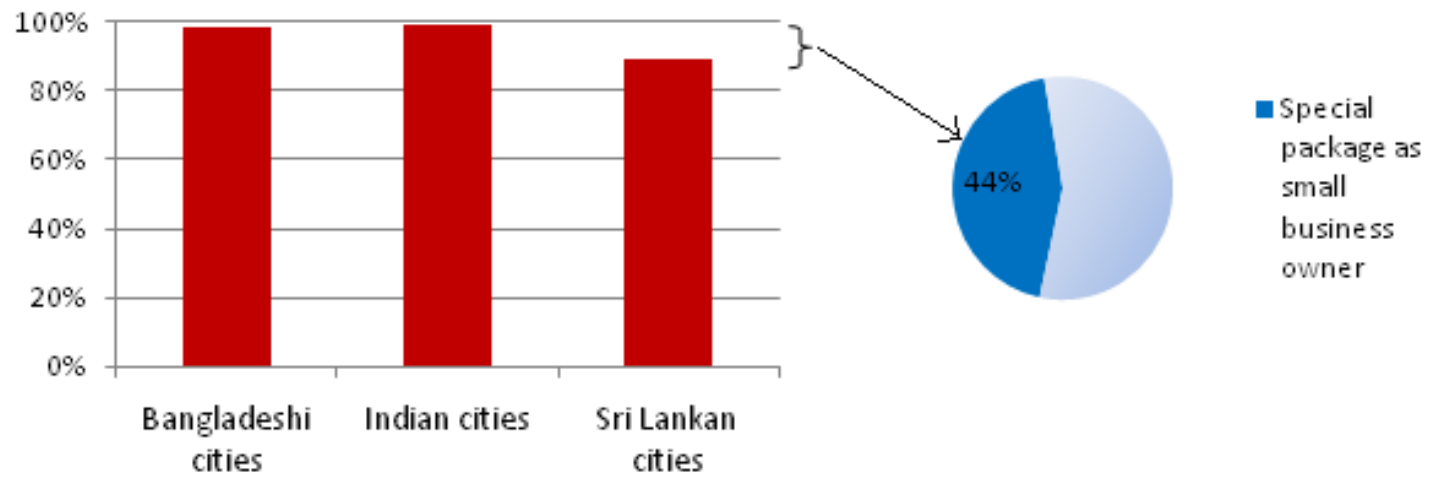

Figure 3: Prepaid vs. Post-paid, ME specific plans

From the MNO perspective the difference prepaid and postpaid is on the billing platform. In fact during the supply side study it was evident that for service providers, prepaid is the preferred mode of use. Although the difference is marginal, the average expenditure of a postpaid user vs. prepaid, among the low-income micro-entrepreneurs is higher (Tables 2).

\begin{tabular}{|l|l|l|l|}
\hline & India & Bangladesh & Sri Lanka \\
\hline BOP prepaid mobile owners (2011) & 1.61 & 1.99 & 3.18 \\
\hline $\begin{array}{l}\text { Low-income micro-entrepreneurs who use prepaid } \\
\text { for business (2013) }\end{array}$ & 8.91 & 6.21 & 10.67 \\
\hline $\begin{array}{l}\text { Low-income micro-entrepreneurs who use post-paid } \\
\text { for business (2013) }\end{array}$ & $\begin{array}{l}\text { The sample consisted of } \\
\text { only prepaid users }\end{array}$ & 12.3 \\
\hline
\end{tabular}

Table 2: Average expenditure of prepaid and post-paid users

Based on both supply and demand side studies, some of the key issues that were highlighted were network coverage related issues, unintentional VAS activation and billing disputes. However, the user perception is that there is no point in complaining about these issues. 50 percent of the survey respondents say they have never contacted the MNO. This causes users to continue with sub-par standards or switch to a competitor if issues persist. Further there seems to be an opportunity in targeting micro-entrepreneurs, as overall they seem to spend more than other low income mobile owners. It is also expected that as micro-entrepreneurs grow, they would continue to be loyal to their original operators, and could generate higher revenue. 


\section{$5 \quad$ Recommendations and Conclusions}

The saturation of mobile services industry has led to intense competition where the operators have to focus on differentiating themselves from the rest of the market players. There seems to be a missed opportunity which MNOs can take advantage of by providing targeted services to microentrepreneurs.

Currently, micro-entrepreneurs are not identified and treated as a different group. This is a missed opportunity for MNOs. There is value in identifying micro enterprises and low income groups that have the potential to develop and in assisting them to expand. As communication is an integral part of the supply chain, MNOs have a significant role to play.

The survey shows that those who use postpaid connections spend more on a monthly basis in comparison to the prepaid uses. Out of those surveyed in Sri Lanka only 11 percent use postpaid connections; out of which only $44 \%$ had signed up for a 'SME' package (Figure 3) targeted for micro or small enterprises, but not specific to low-income users. For low-income micro-entrepreneurs to reveal themselves, they need to see a benefit. The supply-side study confirms that the few SME specific plans offer benefits such as low monthly rental, free minutes / free calls within the group. If MNOs can provide other benefits, there will be incentive for micro-entrepreneurs to sign up. Financial services are one of the key needs for low-income micro-entrepreneurs. MNOs can partner with financial institutions to deliver related services to their customers.

Low-income groups often have financial constraints and have limited access to formal financial services. However, they own and use mobile phones. Due to the lack of assets and information on past transactions, assessing credit worthiness is a challenge. MNOs however have access to transaction generated data (TGD) such as call detail records (CDR), the use of value added services (VAS), the use of financial data (if existing financial services are offered) and the use of Internet. This data can be converted to valuable information that can be used to analyse and create patterns of use. For example the Consultative Group for Assisting the Poor (CGAP) hypothesized that those who top up frequently and consistently demonstrated predictability in income and better planning of financial resources and would therefore have the ability to pay back a loan (CGAP, 2012). A company called Cigfini created a credit scoring model with CDR data in Tanzania and Brazil and tested this hypothesis. The test showed the model was an accurate predictor of default-its scores were positively correlated with the default across the lending portfolio. Although financial services are the most apparent type of VAS for the low-income micro-entrepreneurs, there are others such as matching people to different type of insurance and helping to tailor premiums and pay back methods etc.

In order to capture market, and manage customer relationships, operators in both countries are utilizing Customer Relationship Management (CRM) software, with many capabilities including unified view of the customer, analysis of usage patterns, sending targeted campaigns to specific groups, etc. It seems that with majority of the telecom companies in both countries being multinational subsidiaries, who have financial backing and KPIs from the parent company, they all utilise sophisticated CRM systems. As a result most of their practices are on par with the global giants. However, based on both supply and demand side studies, some of the key issues that were highlighted by those surveyed and the MNOs were network coverage related issues and unintentional VAS activation.

Some possible solutions to improve these issues are: 
To improve network coverage, customers could be given the option of informing service providers via SMS / USSD / or any other relevant mechanism, of areas with coverage or connectivity related issues. This will enable the operator to create a crowd sourced map and look in to potential blind spots to improve their coverage. Often customers do not see a point in complaining to the MNO about network related issues as the perception is that nothing will be done to rectify such issues.

To reduce unintended VAS activation, the customer could receive an automated call or a SMS requesting reconfirmation. It is important that the reconfirmation message has different, i.e. not the default, keys to denote 'Yes' and 'No'. This however, will not benefit the existing notion of receiving too many messaged from the service provider, nor will it solve the language issue (in Sri Lanka the fact that messages from the MNO are not sent in the local script have been highlighted as an issue). Perhaps an opt-in as opposed to opt-out model that is currently used by one of the MNOs will solve the issue to a great extent. Customers are given a free trial of a VAS after which they have $t$ actively opt-in to continue with the service. Most MNOs however, practice the opt-out method at present. After having received multiple complaints, the Telecommunication Regulatory Authority of India (TRAI) has issued a directive to the operators mandating the explicit reconfirmation by customers who subscribe to VAS.

Market saturation and the stagnation or decline of revenues from voice also means that operators are constantly looking for alternative revenue streams. The focus on data and promoting mobile broadband is evident. However, it is generally perceived as a service for the more affluent. The pricing is also not easy to comprehend. Unlike in voice where there is per minute charges, per GB type of pricing can be confusing across all customer segments. The authors have not noticed any attempts of simplifying the pricing of broadband services and therefore it is recommended that operators take active efforts to provide information that will help customers understand the costs and benefits of access to broadband.

Quality of service is an imperative factor to consider. With the budget telecom network model in effect, a down-side is that due to the low charges, the quality of service may also suffer, and the sector may fall into a low quality, low price trap (Samarajiva, 2010). One possible method to overcome this low price, low quality trap, is for regulators to set quality of service benchmarks, measure and regularly report to the public. Currently, this is not being systematically done in Bangladesh or Sri Lanka (except in the case of broadband where the Telecommunication Regulatory Commission of Sri Lanka conducts monthly tests and publishes the results), but TRAI measures and reports on a set of QOS indicators for voice and data quarterly. By making these indicators public, it is expected that the consumers will compare and exit low quality operators in search of better quality and all operators may be forced to meet a minimum quality level.

Overall, it is the view of the authors that analysis of transaction generated data can really be used to enhance the customer experience and provide the MNOs with potential new revenue streams. Just by intelligent segmentation and micro segmentation of the customer base, customers can be provided with relevant services and MNOs can partner with other institutions to provide atypical value added service over the mobile network. Identifying niche markets and diversifying is a necessity for MNOs to survive. 



\section{Acknowledgments}

The authors wish to thank the team at LIRNEasia, The Nielsen Company, CKS Consulting Pvt. Ltd. Vigneswara Ilavarasan and all survey respondents.

\section{References}

Barton J., (2012), Getting to know you: incentivising loyalty through tailored tariffs, Retrieved from http://www.developingtelecoms.com/getting-to-know-you-incentivising-loyalty-through-tailoredtariffs.html

Bayer, J. (2010). Customer segmentation in the telecommunications industry. Journal of Database Marketing \& Customer Strategy Management, 17(3-4), 247-256. doi:10.1057/dbm.2010.21

CGAP. (2012). Can Digital Footprints Lead to Greater Financial Inclusion? Retrieved from http://www.cgap.org/sites/default/files/CGAP-Brief-Can-Digital-Footprints-Lead-to-GreaterFinancial-Inclusion-Jul-2012.pdf

Europa (2003). Definition of micro, small and medium-sized enterprises. Retrieved from http://europa.eu/legislation_summaries/enterprise/business_environment/n26026_en.htm

Gupta, A. (2008). Pursuit of the Perfect Order : Telecommunications Industry Perspectives (pp. 1-14).

Hamill, J. (Department of M. U. of, \& Strathclyde). (n.d.). Customer Management Slideset.

Haridasan, V., \& Venkatesh, S. (2011). CRM Implementation in Indian Telecom Industry Evaluating the Effectiveness of Mobile Service Providers Using Data Envelopment Analysis. International Journal of Business Research and Management, 2(3), 110-127.

Institute of Customer Service. (2011). Improving customer service standards in a regulated, non competitive industry sector a white paper. Retrieved from

https://www.instituteofcustomerservice.com/files/Improving_customer_service_standards_in_a_regula ted_non-competitive_industry_sector.pdf

Maity, M. (2012) The Role of Work-Related Information in the Intention to Continue Using Mobile Telecommunication: Users at the BOP. LIRNEasia. Retrieved from http://papers.ssrn.com/sol3/papers.cfm?abstract_id=2309360

Manuel, N. N., \& Sjolund, M. (2008). Getting more from prepaid mobile services. The McKinsey Quarterly, (february), 0-8.

Metasite. (n.d.). Customer lifecycle marketing system: stop sending the wrong offers at the wrong time. Metasite. Retrieved from http://metasite.net/

Meyer, C., \& Schwager, A. (2007). Understanding Customer Experience. Harvard Business Review.

Ryan W. Buell, Dennis Campbell, Frances X. Frei, working paper (2011), How Do Incumbents Fare in the Face of Increased Service Competition? 11-084 2011, Retrieved from

http://www.hbs.edu/faculty/Publication\%20Files/11-084.pdf 
Samarajiva, R., (2010), Leveraging the Budget Telecom Network Business Model to Bring Broadband to the People. Information Technologies and International Development Journal, Volume 6, SE, Special Edition, 93-97

Starkey, M. W., Williams, D., \& Stone, M. (2002). The state of customer management performance in Malaysia. Marketing Intelligence \& Planning, 20(6), 378-385. doi:10.1108/02634500210445437

Street, C., \& Park, D. (2011). Community research into telecommunications customer service experiences and associated behaviours.

Xevelonakis, E. (2008). Managing event-driven customer relationships in telecommunications. Journal of Database Marketing \& Customer Strategy Management, 15(3), 146-152. doi:10.1057/dbm.2008.12 